\title{
Note from the Outgoing President of Academia Europaea
}

\author{
SIERD A.P.L. CLOETINGH
}

The European Review was launched in 1992, with the first issue being published in 1993. From the beginning, the Review has addressed policy, theory, research and practice across the entire spectrum of science and the humanities, focusing on various aspects that are of current European interest.

As stated in the original programme for development of the European Review, the Review is in no way intended to have the character of an 'in-house' journal for the Academia Europaea. Rather, the objective of the journal is the broader promotion of science and the humanities in their international context, as well as to provide a forum for discussions of subjects of major importance to Europe. A continued feature of the Review from its very beginnings has also been its strong interdisciplinary outlook, thereby providing a means for introducing novel elements into the discussion of subjects that otherwise would not rise above the unexceptional. The first Editor-in-Chief - and inaugural President of the Academia Europaea - Sir Arnold Burgen, FRS, also took the initiative to extend the original programme by introducing 'focus issues', which are devoted to a single topic, dedicated, for instance, to the theme of the annual meeting of the Academia or to other issues of strong European scholarly interest. This aspect was extended and further developed by the second Editor-in-Chief, Theo D'haen, with the introduction of ad hoc supplementary issues. These are usually dedicated issues, publishing collections of thematic papers from major international symposia and on topics of broad interdisciplinary interest, such as for example 'From Books to MOOCs'. The supplements are generally sponsored and are standalone issues. They have the benefit of open access. The target is usually one supplement per volume. Further, and under the editorship of Theo D'haen, the European Review gained a much wider global impact. The demand from authors has increased dramatically, with scholars from around the world keen to publish. Each volume of the Review now consists of six peer-reviewed issues a year, up from the original four issues per volume.

So, through a sustained policy of adherence to quality and interdisciplinarity, the European Review now plays a distinguished role in extending and diffusing knowledge across an ever-developing Europe and globally. In no small measure, we have Theo D'haen to thank for his continuing personal commitment to this 
project since 2007. With his retirement (a term perhaps still to be loosely interpreted), an era of significant growth closes. The Academia Europaea salutes the work he has done both for the Academia and the European Review. By the same token and marked by this first issue of volume 30, we welcome the new Editor-in-Chief, Alban Kellerbauer, and offer to him the best wishes of the Academia Europaea, fully confident that the continued strengthening of the journal is assured. 